DOI: 10.20472/IAC.2019.048.030

\title{
HUNG-CHANG LIAO
}

Chung-Shan Medical University; Chung Shan Medical University Hospital, Taiwan

CHENG-MING CHANG

Institute of Labor, Occupational safety and health, Ministry of Labor, Taiwan

YA-HUEI WANG

Chung-Shan Medical University; Chung Shan Medical University Hospital, Taiwan

\section{THE EXPLORATION OF OCCUPATIONAL SAFETY AND HEALTH IN THE MANUFACTURING INDUSTRIES OF TAIWAN}

\begin{abstract}
:
The paper intended to understand the potentials for improving the existing occupational safety and health management in Taiwan's manufacturing industries. Domestic manufacturing industries have mainly focused on the production management system and the pursuit of profits. Therefore, the management system has not been perfect and hence more likely to increase permanent disabilities, deaths, or economic losses. The study examined the major difficulties the manufacturing industries faced while promoting occupational safety and health in order to find a solution to address the difficulties. The study used the technique of panel discussion to examine and reflect over the core issues. The results show that the biggest problems of occupational safety and health are the indifference and lack of support from employers and workers' misunderstanding about occupational safety and health. The research suggests some recommendations for the government including how to operate, how to revise occupational safety and health act, and how to research to enhance occupational safety and health management. The results of this study not only supply the Ministry of Labor (Taiwan) to plan the strategies of occupational safety and health management but also help the employers and employees improve occupational safety and health management in workplace in order to prevent the occurrence of occupational accidents.
\end{abstract}

\section{Keywords:}

occupational safety and health, occupational disabilities, manufacturing industries, occupational accidents 